\title{
Lipid-Rich Carcinoma
}

National Cancer Institute

\section{Source}

National Cancer Institute. Lipid-Rich Carcinoma. NCI Thesaurus. Code C4152.

A carcinoma characterized by the presence of malignant epithelial cells with clear cytoplasm which contains neutral lipids. A representative example is the lipid-rich breast carcinoma. 